\title{
CHARACTERIZATION OF A PIG-TO-GOAT ORTHOTOPIC LUNG XENOTRANSPLANTATION MODEL TO STUDY BEYOND HYPERACUTE REJECTION
}

Paolo Macchiarini, $\mathrm{MD}, \mathrm{PhD}^{\mathrm{a}}$

Rafael Oriol, MD

Agnès Azimzadeh, $\mathrm{PhD},{ }^{\mathrm{c}}$

Vincent de Montpreville, MD

Philippe Wolf, MD

Philippe Dartevelle, $\mathrm{MD}^{\mathrm{a}}$
Background: A pig-to-goat orthotopic lung xenograft model was developed to test whether depletion of goat xenoreactive antibodies against pig red blood cells would prolong pig lung xenograft survival. Methods: Adult goats with anti-pig xenoreactive antibodies underwent left pneumonectomy followed by orthotopic transplantation of pig left lung (group 1) or immunodepletion of their xenoreactive antibodies by extracorporeal right pig lung perfusion before transplantation without (group 2) or with (group 3) complete clampage of the right pulmonary artery. In group 4, goat left lungs were orthotopically transplanted into pigs and served as negative controls (pig serum does not have anti-goat xenoreactive antibodies). Each study group included 5 animals. Immunosuppression in surviving recipients included cyclosporine and azathioprine. Results: Group 1 recipients died $7 \pm 3$ hours after xenograft reimplantation of severe pulmonary hypertension and dysfunction and vasogenic shock, with little evidence of histologic xenograft injury. Group 2 xenografts had a stable circulatory and respiratory function on reperfusion and survived $9 \pm 4$ days. Group 3 animals also tolerated complete occlusion of the right pulmonary artery, and xenografts assured the total respiratory support for $4 \pm 1$ days. After immunodepletion, goat serum showed no detectable titers of xenoreactive antibodies, which began to reappear by postoperative day 2 , where xenografts showed histologic stigmata of acute (humoral and cellular-mediated) rejection that evolved to a complete xenograft necrose at death. Group 4 xenografts showed scattered features of acute rejection $5 \pm 1$ days after the operation. Conclusions: Pig left lung xenografts can provide prolonged and complete respiratory support after depletion of goat xenoreactive antibodies, but they ultimately necrose once recipient xenoreactive antibodies return to pretransplantation values. (J Thorac Cardiovasc Surg 1999;118:805-14) ung transplantation across widely disparate species L (eg, pig-to-human) is restrained by the hyperacute rejection. This reaction, primarily initiated by preformed anti- $\alpha$-galactosyl ( $\alpha$-Gal) xenoantibodies that are present in human serum and directed against $\alpha$-Gal epitopes expressed on the vascular porcine endothelium, ${ }^{1}$

From the a Department of Thoracic and Vascular Surgery, and HeartLung Transplantation and Experimental Surgical Laboratory, Hôpital Marie-Lannelongue, Le Plessis Robinson, Paris-Sud University; 'bINSERM U 504 Villejuif; and the cLaboratory of Experimental Surgery, Fondation Transplantation, Strasbourg, France.

Supported by the Xenotransplantation project within the European Community program DGXII Biotechnology (shared cost BI04CT97-2242 and concerted action 3026PL950004) and Fondation Transplantation.

Read at the Seventy-ninth Annual Meeting of The American Association for Thoracic Surgery, New Orleans, La, April 18-21, 1999. activates complement and causes irreversible xenograft damage within minutes to hours on revascularization. ${ }^{2-4}$ Although removal or inhibition of these anti- $\alpha \mathrm{Gal}$ xenoantibodies may prolong xenograft survival, ${ }^{5,6}$ this down-regulation is only transitory, and the events occurring beyond the hyperacute rejection are unknown.

Received for publication April 22, 1999; revisions requested July 7, 1999; revisions received July 29, 1999; accepted for publication Aug 13, 1999.

Address for reprints: Paolo Macchiarini, MD, PhD, Department of Thoracic and Vascular Surgery, Heidehaus Hospital (Hannover Medical School), Am Leineufer, 70, 30419 Hannover, Germany (E-mail: pmacchiarini@compuserve.com).

Copyright $\odot 1999$ by Mosby, Inc.

$0022-5223 / 99 \$ 8.00+0 \quad \mathbf{1 2 / 6 / 1 0 2 0 9 1}$ 
Goats and pigs belong to the order of ungulates and, like all the other lower mammals, do not have anti- $\alpha$ Gal natural antibodies in their serum ${ }^{7,8}$; therefore a moderate type of hyperacute rejection could be expected. However, recent evidence exists that other unrecognized non- $\alpha \mathrm{Gal}-$ related humoral factors may trigger hyperacute rejection. ${ }^{6}$ Moreover, goats are far more sensitive to xenogeneic whole blood than other species ${ }^{9}$ and represent a well-established large animal model in cardiothoracic surgery. ${ }^{10-13}$ Therefore we first investigated the existence of natural non- $\alpha \mathrm{Gal}$ xenoantibodies in goats and pigs and, on the basis of these results, tested whether their depletion would prolong an orthotopic xenograft lung in a discordant model.

\section{Material and methods}

Animals and study design. Large White (La Roche Cormier, Vendome, France) outbred pigs weighing 20 to 30 $\mathrm{kg}$ served as lung donors. Similar weight adult goats (Saalen, INRA, Jouy en Josas, France) served as recipients. All animals received care in compliance with the "Principles of Laboratory Animal Care" formulated by the National Society for Medical Research and the "Guide for the Care and Use of Laboratory Animals" prepared by the Institute of Laboratory Animal Resources, National Research Council, and published by the National Academy Press, revised 1996.

The first step of this study was to demonstrate whether the goat/pig combination would be a model of discordant xenotransplantation. This was made by performing blood measurements of natural antibody titers and ex vivo studies of the isolated lungs in both directions. Because these studies provided evidence that adult goats have anti-pig xenoantibodies and not vice versa, we next randomly studied 4 types of orthotopic lung xenotransplantation. Adult goats underwent left pneumonectomy followed by orthotopic transplantation of pig left lung without (group 1) or with (groups 2 and 3 ) immunodepletion of their xenoantibodies by extracorporeal right pig lung perfusion before transplantation; the allocation of the animals was randomly performed. Group 3 goats also had complete clampage of the right pulmonary artery (RPA). In group 4, goat left lungs were orthotopically transplanted into pigs and served as negative controls.

Ex vivo lung xenoperfusion model. Pigs were premedicated with intramuscular ketamine hydrochloride $(25 \mathrm{mg} / \mathrm{kg})$ and atropine sulfate $(1 \mathrm{mg} / \mathrm{kg})$ and anaesthetized with intravenous sodium pentobarbital $(25 \mathrm{mg} / \mathrm{kg})$. Pigs or goat left lungs were then harvested and ex vivo perfused and ventilated according our previously developed model. ${ }^{3}$ The arteriovenous oxygen difference $\left(\mathrm{AVO}_{2}\right.$; milliliters of oxygen per $100 \mathrm{~mL}$ blood) was calculated according to the formula

$$
\mathrm{AVO}_{2}=\left([1.34 \times \mathrm{Hb}] \times\left[\mathrm{S}_{\mathrm{art}}\right]\right)-\left([1.34 \times \mathrm{Hb}] \times\left[\mathrm{S}_{\mathrm{ven}}\right]\right)
$$

where $\mathrm{S}$ is the arterial $\left(\mathrm{S}_{\text {art }}\right)$ or venous $\left(\mathrm{S}_{\mathrm{ven}}\right)$ oxygen saturation and $\mathrm{Hb}$ is hemoglobin concentration (grams per deciliter). Blood flow (flow probe, Statham SP2202; Biomedical
Division, Oxnard, Calif) and pulmonary artery pressure (millimeters of mercury per milliliter per minute; Kipp and Zonen BD112, Amsterdam, The Netherlands) measurements allowed calculation of the pulmonary vascular resistance (PVR) as pulmonary artery pressure (millimeters of mercury) and blood flow (milliliters per minute).

Orthotopic left lung transplantation. Pig left lungs acting as xenografts to be implanted orthotopically were harvested as for the ex vivo model. The right lung and middle lobe and the heart of the same pig donor absorbed goat xenoantibodies after the following areas were stapled: (1) origin of the pulmonary trunk and left pulmonary artery, (2) right and left pulmonary veins beyond their left atrium takeoff, (3) venae cavae, and (4) left main bronchus. The ascending aorta was sutured with a continuous 6-0 Prolene suture (Ethicon, Inc, Somerville, NJ) just before the origin of the 2 coronary arteries to avoid myocardial perfusion. These xenografts were then placed in 2 sterile plastic bags containing cold $\left(4^{\circ} \mathrm{C}\right)$ Euro-Collins solution.

Goats were premedicated with acepromazine (0.05-0.1 $\mathrm{mg} / \mathrm{kg})$ and atropine sulfate $(0.2 \mathrm{mg} / \mathrm{kg})$ and anesthetized with intravenous sodium pentobarbital $(1 \mathrm{mg} / \mathrm{kg})$. Adequacy of ventilation and oxygenation was assessed by arterial blood gas analysis and pulse oximeter (Finger Pulse Sensor; Epic Medical, Plano, Tex). They were subsequently selectively intubated through an endotracheal double-lumen tube and ventilated at $100 \%$ oxygen by a mechanical ventilator (Siemens, Elema, Sweden; tidal volume of $15 \mathrm{~mL} / \mathrm{kg}$ at $17-$ 20 breaths/min with $5 \mathrm{~cm} \mathrm{H}_{2} \mathrm{O}$ positive end-expiratory pressure). Light anesthesia was maintained with $1 \%$ to $2 \%$ fluothane (Halotane; Zeneca Pharma, Cergy, France). A left posterolateral thoracotomy in the 4th intercostal space was the usual approach to enter the left pleural cavity, and $1 \mathrm{mg}$ pancuronium bromide was injected intra-arterially as needed for complete muscle relaxation.

The left internal thoracic artery was dissected, and a polyvinyl catheter was inserted to record blood pressure and heart rate with a pressure transducer (Kipp and Zonen) and to serve as an arterial sampling line. After the division and ligation of the pulmonary inferior ligament and a left lower vein that drained the right middle lobe, the pericardium was opened; the aortopulmonary ligament was ligated, and the pulmonary trunk and RPA were dissected and encircled. We next placed polyvinyl catheters and flow probes into the left atrium, right appendage, and in and around the thoracic aorta, pulmonary trunk, and origin of the RPA to measure systemic and pulmonary pressures and cardiac output (Statham SP2202; Biomedical Division).

In goats of group 1, pig left-lung xenografts were immediately orthotopically implanted with the use of the standard implantation technique. In goats of groups 2 and 3, goat cardiac output was first passed for at least 15 minutes into pig right lung-middle lobe and heart block to immunoabsorb the goat xenoantibodies (Fig 1). At completion, pig left lungs were implanted. Goats in group 3 also underwent ligation of the RPA. The pleural spaces were then closed with 2 chest 
tubes, and the chest wall was closed with interrupted polyglactin 1 sutures.

Hemodynamics. The following hemodynamic determinations were made at baseline and during the first hour after the transplantation: (1) mean arterial pressure (millimeters of mercury), heart rate (beats/minute), cardiac output (CO; liters/minute), and pulmonary trunk and left pulmonary artery flow (liters/minute); (2) systemic vascular resistance (dyne-sec/ $\mathrm{cm}^{5}$ as mean arterial pressure - central venous pressure/CO $\times 80$ ), PVR (dyne-sec/ $\mathrm{cm}^{5}$ as mean pulmonary artery pressure - left atrial pressure/ $\mathrm{CO} \times 80$ ); (3) arterial and venous partial pressure of oxygen $\left(\mathrm{PO}_{2}\right)$ and partial pressure of carbon dioxide $\left(\mathrm{PCO}_{2}\right), \mathrm{pH}$ (ABL3; Radiometer, Copenhagen, Denmark). The alveolar-arterial oxygen difference $\left[\mathrm{D}(\mathrm{A}-\mathrm{a}) \mathrm{O}_{2}\right]$ was measured as follows:

$$
\left[\mathrm{D}(\mathrm{A}-\mathrm{a}) \mathrm{O}_{2}\right]=\left(\mathrm{FIO}_{2}\right)(713)-\mathrm{PO}_{2}-\mathrm{PCO}_{2} / 0.8
$$

Medical support and immunosuppression. Before xenograft reperfusion, recipients received $1 \mathrm{~g}$ of indomethacin to block thromboxane production. Animals received intravenous antibiotics (cephalothin, $500 \mathrm{mg} /$ daily), oral acetylsalicylic acid (100 mg/daily) and prednisolone (40 mg, days 1 and 3 after the operation), and intramuscular cyclosporine (INN: ciclosporin) $(5-10 \mathrm{mg} / \mathrm{kg} /$ day) to maintain plasma levels of 250 to $350 \mathrm{ng} / \mathrm{mL}$ and oral azathioprine $(2.5 \mathrm{mg} / \mathrm{kg}$ daily). Animals were placed in cages and fed standard laboratory food and water ad libitum.

Fiberoptic tracheal and chest radiographic examinations were performed daily. Open lung biopsies were performed 2 and 4 days after the operation. Animals were killed at the clinical or histologic occurrence of xenograft necrosis or at the first evidence of discomfort.

Dilution effect. Plasma dilution was assessed by the measurement of total plasma protein levels, as described previously. ${ }^{14}$ No dilution of plasma was evidenced after pig lung perfusion, whereas a dilution of 1.6- \pm 0.15 -fold was observed in plasma after pig lung transplantation (as compared with plasma before transplantation).

Measurement of serum xenoantibodies and their elution from lung tissue. Serum samples were obtained from donors and recipients before and daily after xenotransplantation to measure xenoantibody titers by hemagglutination. Pig red cells were washed 3 times with 20 volumes of phosphate-buffered saline solution (PBS). Twofold serially diluted $50 \mu \mathrm{L}$ aliquots of goat serum and lung eluates were tested against equal volumes of $2 \%$ pig red cells in PBS, and results were expressed as the reciprocal of the highest dilution at which agglutination was observed. After perfusion with goat whole blood, the right immunoabsorbent lungs were washed with PBS, then the fixed antibodies were eluted with $\mathrm{NH}_{4} \mathrm{OH} 1 \%(\mathrm{pH} \mathrm{11)}$. Aliquots of $50 \mathrm{~mL}$ of eluate were collected and dialyzed against PBS and stored frozen at $-20^{\circ} \mathrm{C}$ until used.

Preparation of endothelial cell extracts. Porcine endothelial cells were explanted from the aorta of large White pigs and cultured until confluence in Roswell Park Memorial Institute medium that contained $20 \%$ fetal calf serum and 1

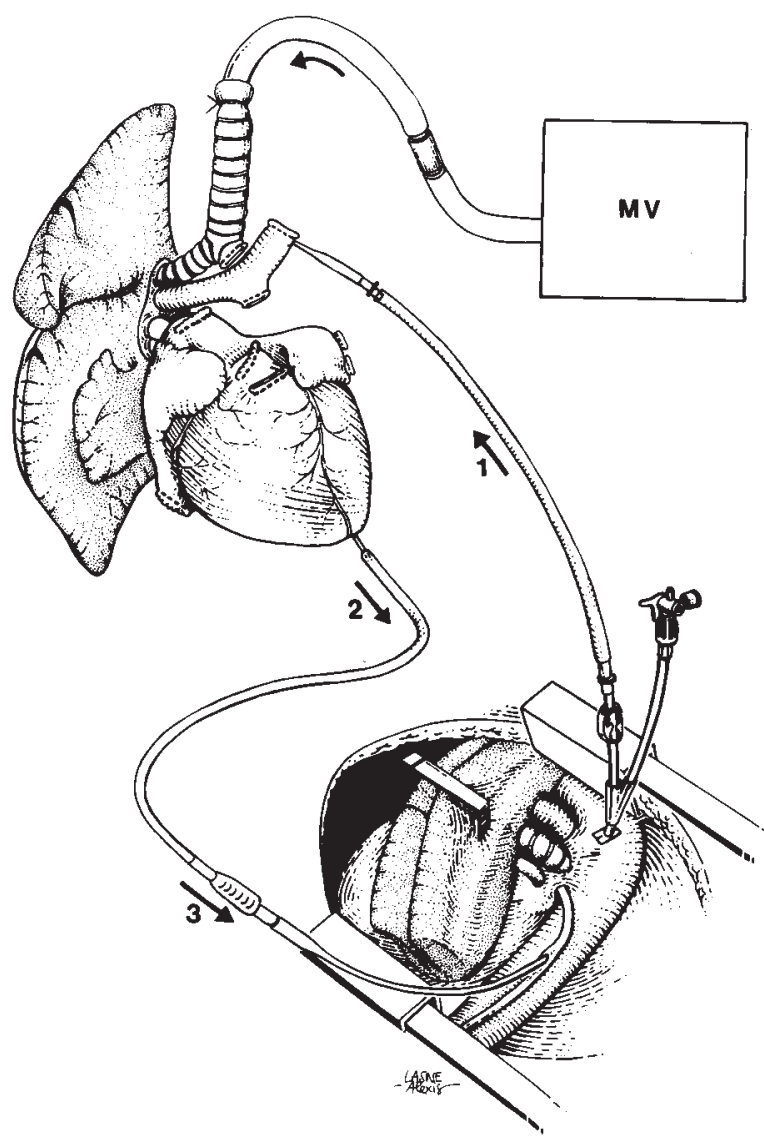

Fig 1. An aortic root cannula (DLP, Inc, Grand Rapids, Mich) was inserted into the descending aorta and connected to a tubing system and a cannula (William Harvey, CR Bard, Inc, Tewsburg, Mass) to allow the anterograde flow of goat cardiac output through pig right lung, middle lobe, and heart. A venting multihooled catheter drained the immunoabsorbed blood into the distal left azygos vein. During this immunoabsorption time, the right lung and middle lobe were ventilated through a mechanical ventilator $(M V)$ to avoid gas embolism. To measure transpulmonary pressure and/or stabilize the recipient during this procedure, a pressure transducer was connected to the tubing system, and intermittent tubing clamps and peripheral vasoconstrictive and inotropic agents were used.

mmol/L sodium pyruvate, as described previously. ${ }^{14}$ Endothelial cell monolayers were washed, scraped from the flasks, and pelleted by centrifugation at $900 \mathrm{~g}$ for 5 minutes. The cells were resuspended and lysed in 1 volume of $50 \mathrm{mmol} / \mathrm{L}$ Tris-hydroxymethyl-amino methane (Tris; $\mathrm{pH}$ 7.2) containing 2\% t-octylphenoxypolyoxyethanol (Triton X-100), $5 \mathrm{mmol} / \mathrm{L}$ ethylenediaminetetra-acetic acid and Pefablock, $1 \mathrm{mmol} / \mathrm{L}$ benzamidine, $15 \mu \mathrm{mol} / \mathrm{L}$ pepstatin and $10 \mu \mathrm{mol} / \mathrm{L}$ leupeptin for 30 minutes on ice. After centrifugation at $10,000 \mathrm{~g}$ for 30 minutes, the supernatant was collected and stored at $-70^{\circ} \mathrm{C}$ until used. 

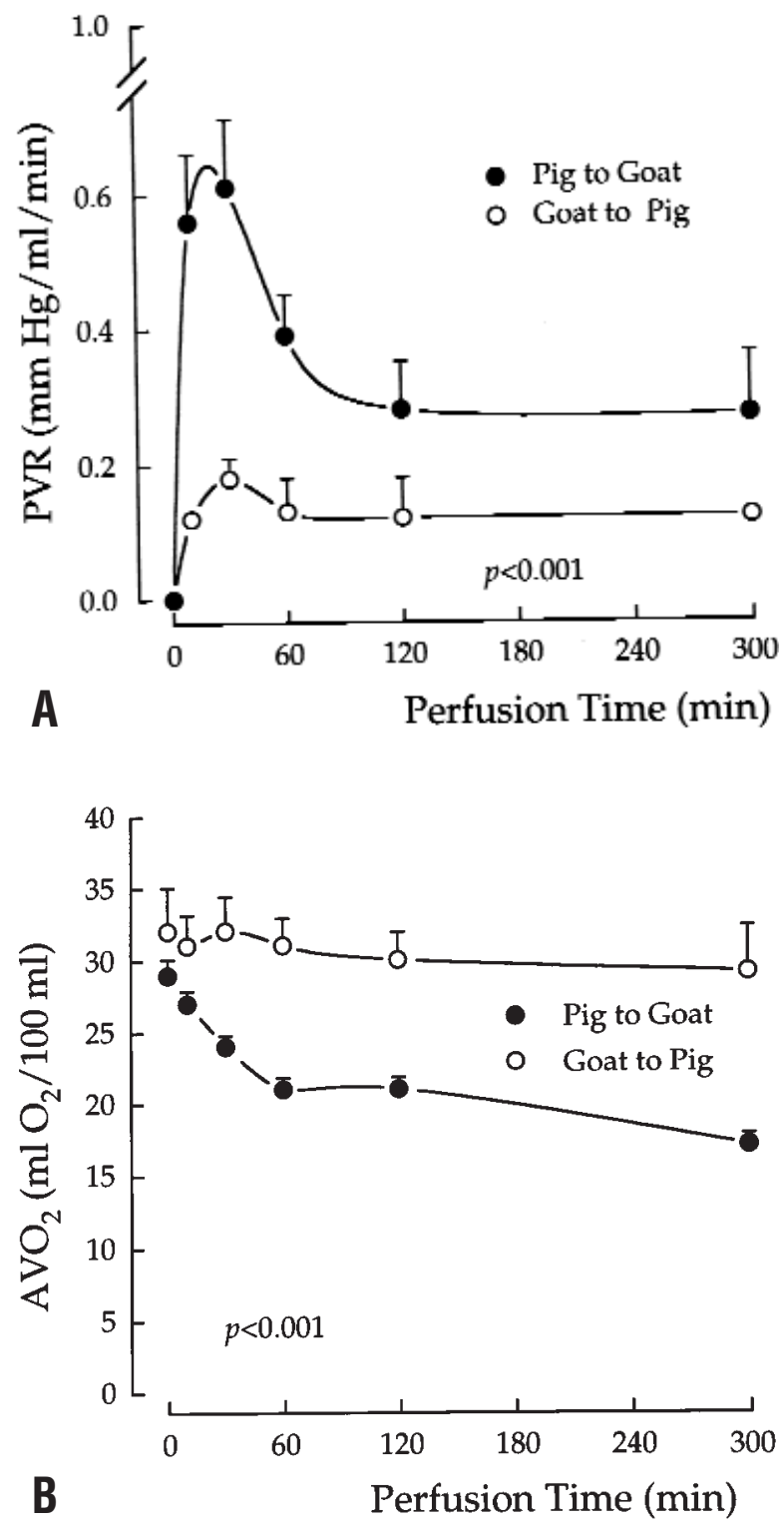

Fig 2. Hemodynamics (A) and oxygen extraction (B) at baseline (time 0 ) and at specific time intervals after ex vivo lung xenografts perfusion with either goat or pig blood. Data are expressed as mean $\pm \mathrm{SD}$ (error bars) of the experiments. The difference was statistically significant $(P<.001)$. During the time interval between -30 and 0 minutes, the xenografts were perfused with autogenic blood to stabilize the perfusion system; before reperfusion, they were washed with $1.5 \mathrm{~L}$ saline solution to avoid hemolyzation of the residual autogenic blood.

Sodium dodecylsulfate-polyacrylamide gel electrophoresis and Western blot analysis. To characterize the specificity of anti-pig antibodies that were removed after pig lung transplantation or pig lung perfusion, the reactivity of native and xenoantibody-depleted goat serum samples was analyzed on porcine endothelial cell extracts.
Samples of pig endothelial-cell extracts were electrophoresed on a $7.5 \%$ gel under reducing conditions. Proteins resolved in this way were transferred to $0.45 \mu \mathrm{m}$ polyvinylidene difluoride membranes. ${ }^{14}$ After saturation with $3 \%$ lowfat dry milk in Tris-buffered saline solution (TBS) overnight at $25^{\circ} \mathrm{C}$, the membranes were washed 3 times with $0.3 \%$ Tween-20 in TBS and stored in this buffer until used. Goat sera (diluted 1:20 in TBS) or lung eluates (diluted 1:20, 1:10, and $1: 5$ in TBS) were incubated overnight at $25^{\circ} \mathrm{C}$. After being washed with $0.3 \%$ Tween- 20 in TBS, the antibody binding was detected by incubating blots with alkaline phosphatase-conjugated affinity purified rabbit anti-goat IgG $(\mathrm{H}+\mathrm{L}$; The Jackson Laboratories, Bar Harbor, Maine) diluted $1: 1000$ in $0.5 \%$ bovine serum albumin in TBS for 2 hours at $25^{\circ} \mathrm{C}$. The expression of $\alpha$-Gal residues was analyzed with biotinylated isolectin B4 from Griffonia simplicifolia (GSIB4) as described previously. ${ }^{15}$ The immunoblots were revealed with nitroblue tetrazolium (Biorad, Hercules, Calif).

Histologic information. Xenografted and recipient native lungs were macroscopically assessed. At least 4 samples of representative areas were taken, and fragments were fixed in $10 \%$ formaldehyde and routinely processed into paraffin wax. Sections were cut at $5 \mu \mathrm{m}$ and stained with hematoxylin and eosin.

Statistical analysis. In the ex vivo model, xenograft failure was defined as such when the ex vivo lung perfusion was associated with no gas exchange, severe pulmonary hypertension, and gross evidence of pulmonary hemorrhage and edema. In the orthotopic model, experiments were stopped at the onset of recipient discomfort or xenografts dysfunction. Data are expressed as mean \pm SD of the number of observations and analyzed by 1-way analysis of variance with Fisher's protected least significance difference (StatView 4.02; Abacus Concepts, Inc, Berkeley, Calif). The a priori level of significance was set at a $P$ value of less than .05 .

\section{Results}

Ex vivo lung studies. Goat sera contains xenoantibodies to pig red cells, but pig serum demonstrated no detectable titers of xenoantibodies against goat red blood cells. Unsurprisingly, goat lungs perfused with pig blood displayed almost normal xenograft function over the entire 5-hour study period, although a marked pulmonary hypertension and fall in $\mathrm{AVO}_{2}$ occurred when pig lungs were perfused with goat blood (Fig 2), but both ex vivo models were working after the 5-hour study period. Goat anti-pig xenoantibodies fall from $6.4 \pm 1.6$ before the ex vivo perfusion to $0.8 \pm 1.0$ on completion of the study period. Goat lungs perfused with pig blood were normal, although pig lungs perfused with goat blood were congested and edematous without pulmonary microvessel thrombosis (Fig 3).

Orthotopic left lung transplantation. All goats belonging to group 1 died $7 \pm 3$ hours after pig 


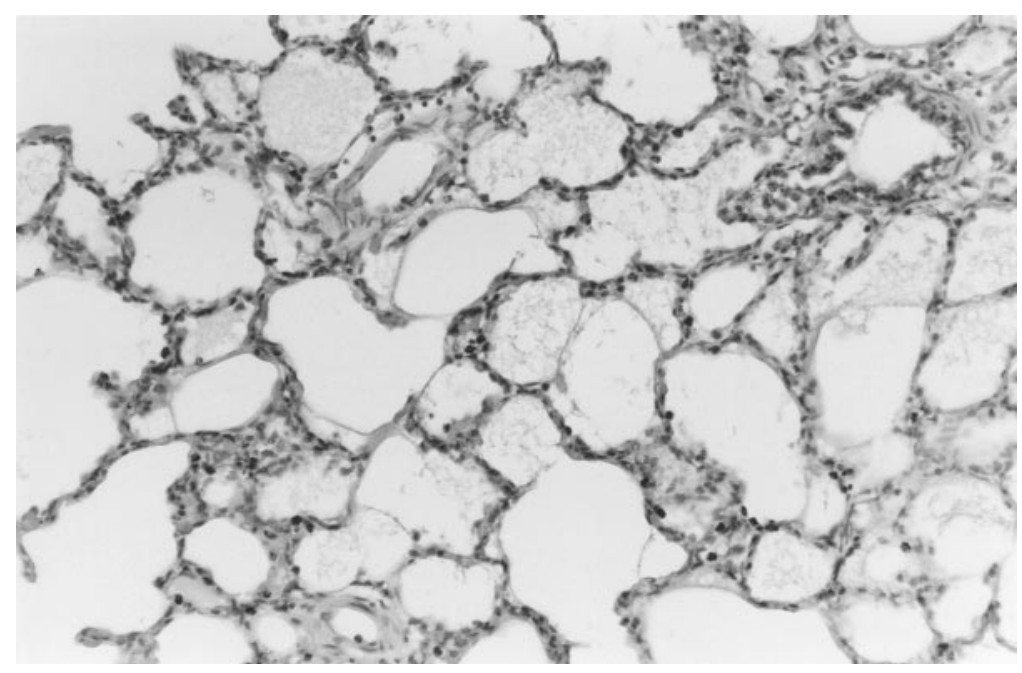

Fig 3. Histologic features of pig lungs perfused with goat blood, displaying alveolar edema but no microvessel thrombosis. Biopsy specimens were taken at the experiment's completion. (Original magnification, $\times 180$.)

Table I. Posttransplantation (1-hour) hemodynamics in goats that underwent left lung orthotopic transplantation of pig xenografts without (group 1) and with depletion of the goats xenoreactive antibodies and without (group 2) or with (group 3) clampage of the RPA

\begin{tabular}{|c|c|c|c|c|c|c|}
\hline Timing & $\begin{array}{c}H R \\
\left(\text { beats } \times \text { min }^{-1}\right)\end{array}$ & $\begin{array}{c}C O \\
(L / \min )\end{array}$ & $\begin{array}{c}S V R^{*} \\
\left(\text { dyne-sec/ } \mathrm{cm}^{5}\right)\end{array}$ & $\begin{array}{c}\text { Xenograft } P V R^{\dagger} \\
\left(\text { dyne-sec/ } / \mathrm{cm}^{5}\right)\end{array}$ & $\begin{array}{c}D(A-a) O_{2} \\
\text { on } 100 \% \text { oxygen }\end{array}$ & $\begin{array}{c}A P \\
(m m H g)^{\S}\end{array}$ \\
\hline \multicolumn{7}{|l|}{ Group 1} \\
\hline Baseline & $92 \pm 5$ & $4.2 \pm 0.7$ & $1479 \pm 259$ & $172 \pm 24$ & $281 \pm 17$ & $10 \pm 1$ \\
\hline 10-min & $79 \pm 14$ & $3.5 \pm 0.5$ & $1041 \pm 229$ & $462 \pm 95$ & $404 \pm 48$ & $19 \pm 1$ \\
\hline 30-min & $88 \pm 4$ & $3.5 \pm 0.9$ & $982 \pm 288$ & $413 \pm 86$ & $453 \pm 48$ & $24 \pm 1$ \\
\hline 60-min & $85 \pm 10$ & $3.5 \pm 0.2$ & $727 \pm 231$ & $426 \pm 86$ & $481 \pm 48$ & $24 \pm 1$ \\
\hline \multicolumn{7}{|l|}{ Group 2} \\
\hline Baseline & $106 \pm 8$ & $4.1 \pm 0.5$ & $1693 \pm 356$ & $183 \pm 42$ & $298 \pm 11$ & $10 \pm 1$ \\
\hline 10-min & $106 \pm 13$ & $3.6 \pm 0.5$ & $1697 \pm 383$ & $238 \pm 59$ & $338 \pm 18$ & $14 \pm 1$ \\
\hline 30-min & $104 \pm 6$ & $3.2 \pm 0.5$ & $2054 \pm 444$ & $271 \pm 22$ & $354 \pm 11$ & $14 \pm 1$ \\
\hline 60-min & $105 \pm 7$ & $3.3 \pm 0.8$ & $2021 \pm 585$ & $250 \pm 64$ & $361 \pm 4$ & $14 \pm 1$ \\
\hline \multicolumn{7}{|l|}{ Group 3} \\
\hline Baseline & $109 \pm 15$ & $4.1 \pm 1.2$ & $1694 \pm 479$ & $255 \pm 28$ & $286 \pm 5$ & $10 \pm 1$ \\
\hline 10-min & $96 \pm 19$ & $3.6 \pm 0.2$ & $2038 \pm 764$ & $317 \pm 4$ & $361 \pm 7$ & $14 \pm 1$ \\
\hline 30-min & $100 \pm 7$ & $3.3 \pm 0.5$ & $2514 \pm 584$ & $357 \pm 3$ & $366 \pm 2$ & 15 \\
\hline 60-min & $95 \pm 10$ & $3.3 \pm 0.6$ & $2330 \pm 598$ & $347 \pm 6$ & $377 \pm 5$ & $17 \pm 2$ \\
\hline
\end{tabular}

$H R$, Heart rate; $S V R$, systemic vascular resistance; $A P$, airway pressure.

Results are expressed as (mean $\pm \mathrm{SD}$ ) values.

${ }^{*}$ The systemic vascular resistance of group 1 goats dropped significantly as compared with its increase in group $2(P=.02)$ and $3(P=.03)$ goats, although the reduction of the $\mathrm{CO}$ was not different among the groups over time.

'Although there was no overall difference in PVR among the 3 groups, xenograft PVR increased more in group $1(P=.008)$ and $3(P=.02)$ goats as opposed to group 2 goats.

Gas exchange were significantly worse in group 1 goats than group $2(P=.001)$ and $3(P=.01)$ goats.

${ }^{\S}$ Airway pressure was significantly more increased over time in goats belonging to group 1 than in those belonging to group $2(P<.0001)$ and $3(P<.0001)$.

xenograft reimplantation because all were unweanable from respiratory support because of severe pulmonary hypertension and dysfunction and vasogenic shock (Table I). The native lungs and xenografts showed little evidence of histologic xenograft injury (Fig 4). In this 7- \pm 3 -hour period, the goat anti-pig xenoantibodies declined only slightly from $5.8 \pm 1.0$ before to 2.5 \pm 0.6 after engraftment, and this decrease probably reflected more a dilution effect than specific antibody removal. 


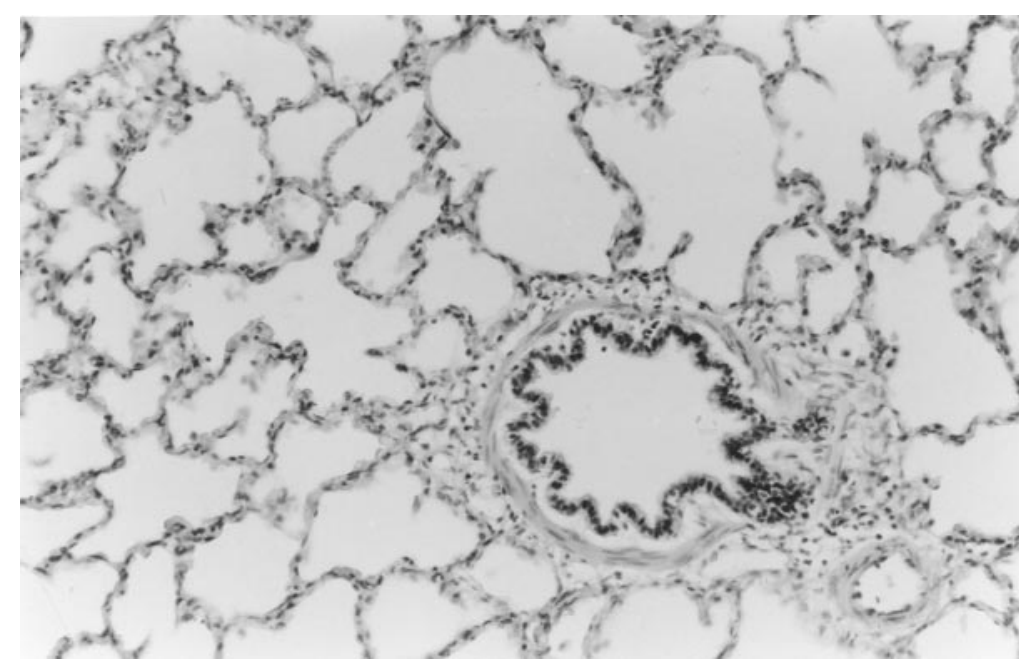

Fig 4. Histologic features of pig left lungs orthotopically implanted into the goats show a normal structure, except the presence of rare peribronchial inflammatory cells. Biopsy specimens were taken at the experiment's completion. (Original magnification, $\times 50$.)

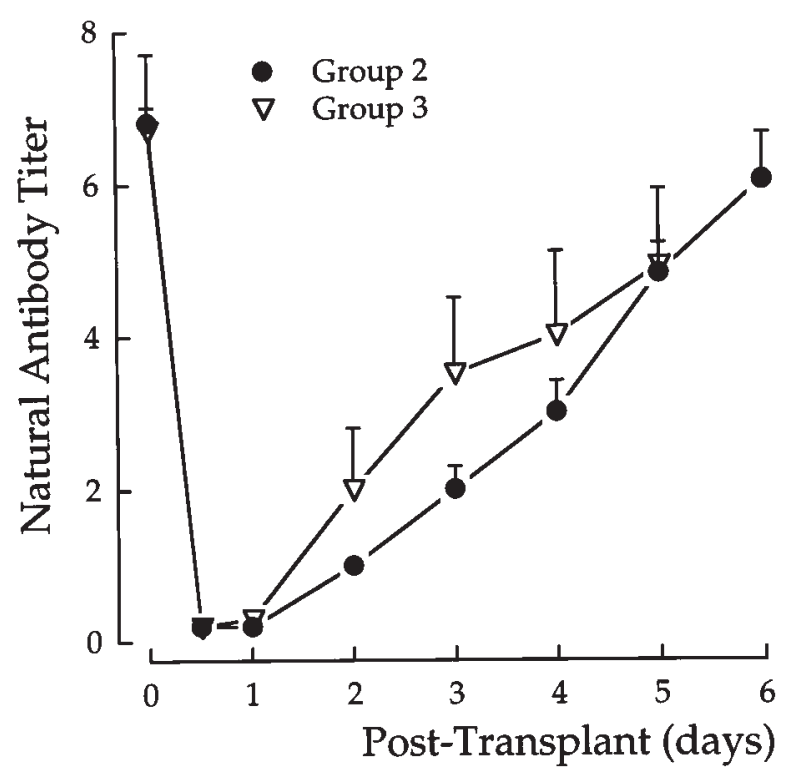

Fig 5. Natural anti-pig xenoantibodies detected by standard hemagglutination in goat sera. The rise of xenoantibodies was earlier for group 3 than for group 2 goats. The xenoantibodies were expressed as the reciprocal of the highest dilution at which agglutination was observed.

On reperfusion, group 2 xenografts had stable cardiocirculatory and respiratory functions as compared with group 1 xenografts (Table I), and the animals survived for $9 \pm 4$ days. Group 3 animals also tolerated complete occlusion of the RPA, and the xenografts assured total respiratory support for $4 \pm 1$ days. Pig immunoabsorbent organs were congested and associated with intra-alveolar hemorrhage without microthrombosis. After immunodepletion, serum of goat belonging to groups 2 and 3 showed no detectable titers of xenoantibodies, but the titers began to increase significantly $(P<.0001) 1$ to 2 days after transplantation and reached pretransplantation levels by days 4 (group 3) to 6 (group 2; Fig 5). This xenoantibody time course paralleled the aggravation of xenograft rejection because the acute vascular rejection (Fig 6) constantly documented 2 days after the transplantation progressed to a complete xenograft necrosis (Fig 7) at death in all goats. However, the acute vascular rejection was predominantly humoral mediated (endothelial hyperplasia and interstitial congestions) in group 2 goats and cellular mediated (perivascular and peribronchial lymphoid infiltration) in group 3 goats. Xenograft necrosis typically spared recipient's bronchial, pulmonary artery, and left atrium stumps of the recipients. All group 4 pigs were killed $5 \pm 1$ days after the transplantation, and xenografts displayed scattered features of acute rejection.

Western blot analysis of goat anti-pig natural antibodies. At baseline, at least 10 bands that corresponded to proteins with apparent molecular weights ranging from 20 to $280 \mathrm{kd}$ were detected by goat antibodies (Fig 8, lanes 1 and 3). In orthotopic group 1 goats, the pattern of reactivity was unchanged (Fig 8, lane 2). In the pig organs used to absorb goat anti-pig xenoantibodies, (groups 2 and 3), binding of goat antibodies to the $180,130,50,30,26$ and $20 \mathrm{kd}$ proteins 

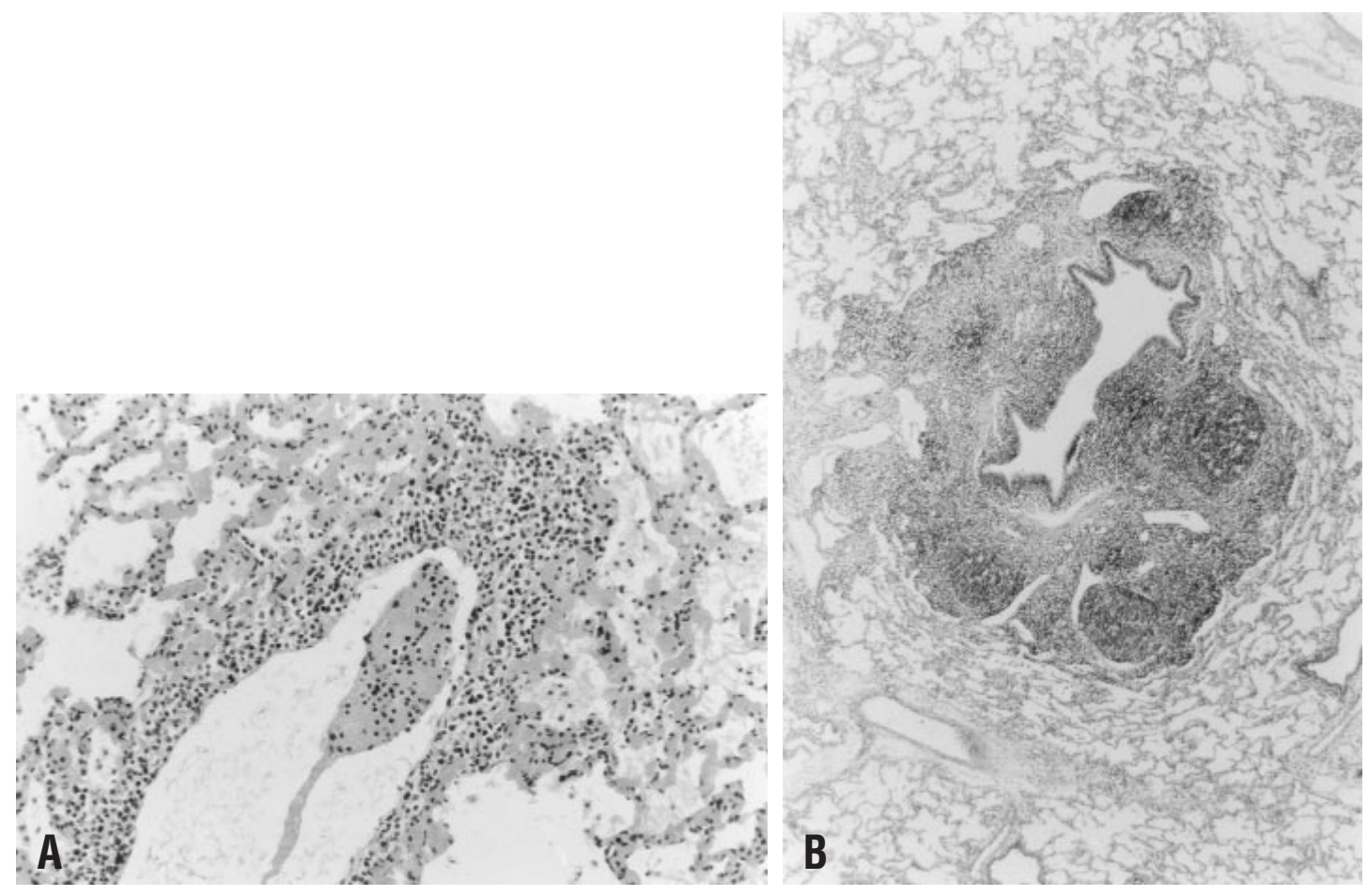

Fig 6. A, Biopsy specimen taken at day 2 shows signs of mild vascular rejection, as demonstrated by the presence of lymphoid infiltration within the wall of a pulmonary venule (group 2; original magnification, $\times 50)$ or $(\mathbf{B})$ severe rejection as demonstrated by an aspect of follicular lymphocytic bronchiolitis (group 3; original magnification, $\times 12.5)$.

was removed, whereas binding to other proteins was unchanged or slightly decreased (Fig 8, lane 4).

To further analyze antibody depletion after pig lungs used to immunodeplete goats anti-pig xenoantibodies, we studied the reactivity of antibodies eluted from perfused pig lungs. Fractions of eluate aliquots were tested for anti-pig antibody activity by enzyme-linked immunosorbent assay, with porcine platelet extracts as antigen (data not shown). In these conditions, goat antipig natural antibodies titers (defined as inverse of dilution for optic density $=0.5$ ) varied between 2 and 32 , depending on the experiment and aliquot sample. Eluates with high antibody activity (titer, $>16$ ) were analyzed in Western blot. The reactivity of eluted antibodies for 2 independent experiments is shown in Fig 8 (lanes 5 and 6). At least 8 bands corresponding to proteins with apparent molecular weights between 26 and $205 \mathrm{kd}$ were revealed by goat antibodies eluted from pig lungs perfused with goat blood. Major reactivity was associated with low (lane 5) or high (lane 6) molecular weight bands, depending on the experiment, and in each case was different from the pattern of reactivity observed with the G simplicifolia isolectin B4 (lane 7).

\section{Discussion}

The goat and pig combination represent, despite their phylogenetic vicinity, a promising $\alpha$-Gal antibody-free model, which permits the study of discordant orthotopic lung xenotransplantation beyond the occurrence of hyperacute rejection. Although its clinical relevance may remain unclear, we have confirmed in vivo our previous ex vivo hypotheses that a variety of non- $\alpha \mathrm{Gal}$ antibodies may trigger hyperacute rejection as well. ${ }^{6}$ Moreover, by depleting these non- $\alpha \mathrm{Gal}$ antibodies with a cross-perfusion of pig immunoadsorbent organ, hyperacute rejection may be prevented and complete xenograft function and survival can be prolonged temporarily. We also provided evidence that xenograft failure depends on the reappearance of anti-pig xenoantibodies in recipient goats and confirmed that conventional immunosuppression does not alter this outcome at all. ${ }^{1}$

In the ex vivo perfusion model, pig lung xenografts were working after a 5-hour perfusion with goat blood, despite severe pulmonary hypertension and oxygen dysfunction. By contrast, the same situation in the untreated orthotopic model was characterized by the occurrence 


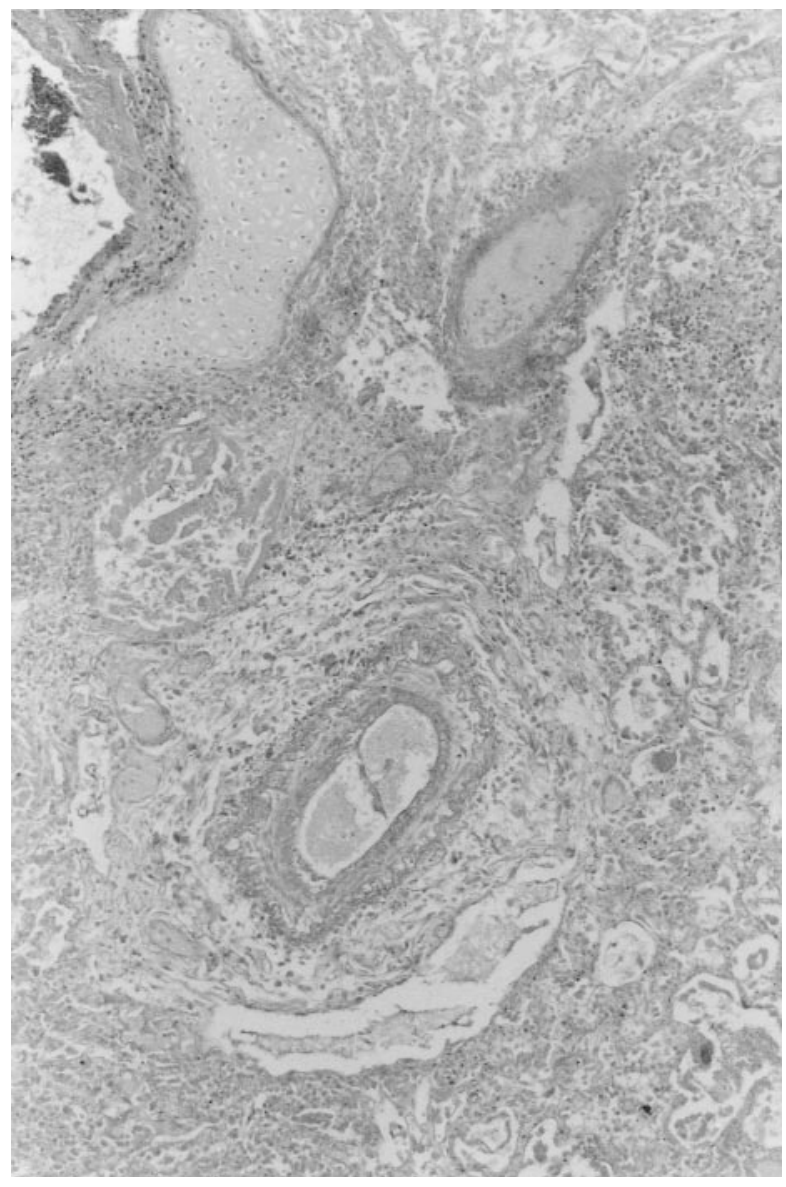

Fig 7. The same pig xenotransplanted lung (as illustrated on Fig 6) shows a complete ischemic necrosis without inflammatory cells (postoperative day 6 ). (Original magnification, $\times 25$.)

of refractory severe pulmonary hypertension and dysfunction and vasogenic shock, leading to death in $7 \pm 3$ hours after xenograft reperfusion. One may argue that this difference may be related to the intrapulmonary or systemic synthesis of thromboxane in goats. ${ }^{9}$ However, the thromboxane activity was always neutralized by intravenous administration of indomethacin before xenograft reperfusion. Yet, the only design difference between goats experiencing (group 1) or not experiencing (groups 2 and 3) circulatory and pulmonary failure was the cross-perfusion of pig organ. Curiously, this clinical scenario was associated with little histologic xenograft injury except alveolar edema, and we may assume that this and the absence of pulmonary microvessel thrombosis may be related to the limited goat blood flow through the pig xenograft because of the severe pulmonary hypertension.

By cross-perfusing goat blood through pig im-

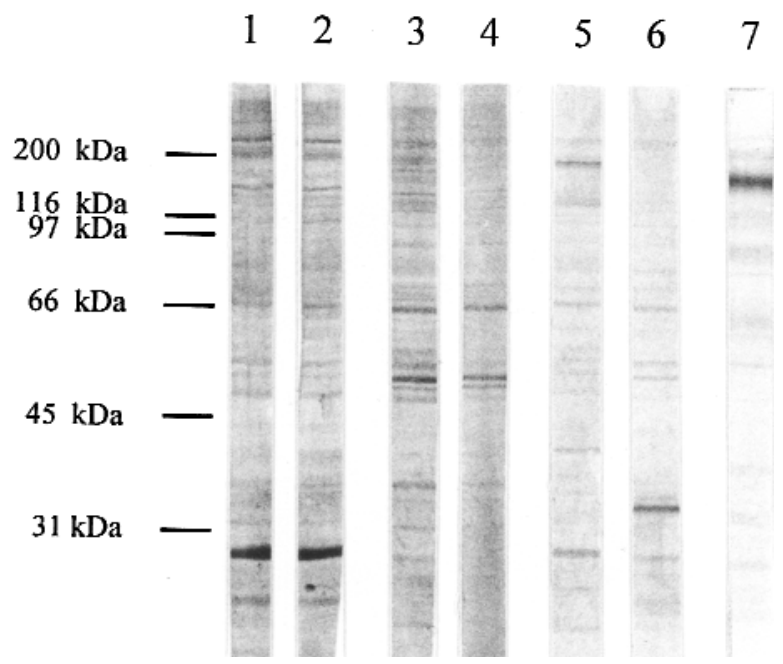

Fig 8. Western blot analysis of the reactivity of goat anti-pig natural antibodies. Porcine aortic endothelial cells membrane extracts were separated by sodium dodecyl sulfate-polyacrylamide gel electrophoresis, blotted onto polyvinylidene difluoride, and stained as follows: lane 1, goat serum, before in vivo pig lung transplantation; lane 2 , goat serum, after in vivo pig lung transplantation; lane 3, goat serum, before ex vivo pig lung perfusion; lane 4, goat serum, after ex vivo pig lung perfusion; lanes 5 and 6, eluates from 2 independent lung perfusion experiments; lane 7, G simplicifolia isolectin B4. Antibody binding was revealed with alkaline phosphataseconjugated rabbit anti-goat $\operatorname{IgG}(\mathrm{H}+\mathrm{L})$ antibodies.

munoabsorbent organs, which retained the anti-pig antibodies, we were able to prevent hyperacute rejection; and our immunologic evaluation clearly demonstrated that this phenomenon was related to the disappearance of anti-pig xenoantibodies from the circulation of the recipients. Using Western blot analysis of the eluted antibodies, we demonstrated that goat antibodies recognize numerous protein bands on porcine endothelial cells. This result is in line with the reactivity observed in other discordant species ${ }^{15-17}$ and with our previous ex vivo observation that multiple human anti-pig xenoantibodies were absorbed on perfusion of pig lungs with human blood. ${ }^{6}$ Unsurprisingly, the pattern of reactivity did not parallel the presence of $\alpha$-Gal-bearing proteins, as assessed with the $G$ simplicifolia isolectin B4. Whether goat anti-pig natural antibodies belong to an homogeneous repertoire with limited specificity against a common epitope shared by target proteins (as $\alpha$-Gal epitope for the pig-to-primate combination) is not known. The complement or complement cascade may have also played an unspecific triggering role, as in other discordant models, ${ }^{18}$ even in 
the presence of very low xenoantibody titers. However, because there are no specific reagents to test goat complement, we could not test this hypothesis.

Yet, even when hyperacute rejection was prevented and xenografts assured complete respiratory support, they ultimately were rejected and became necrosed. The first step of this rejection process was the appearance of an acute vascular rejection similar to that observed in lung allotransplantation where perivascular or peribronchial lymphoid infiltration are found. Of note, the acute vascular rejection included stigmates of both humoral-mediated and cellular-mediated xenograft rejection. The humoral-mediated rejection included endothelial hyperplasia and interstitial congestions, and this corresponded well to the working hypothesis that acute vascular rejection arises under conditions in which hyperacute rejection is avoided and is governed by the physiologic state of the vascular endothelial cell. ${ }^{19}$ The cellular-mediated rejection included perivascular and/or peribronchial lymphoid cell infiltration, and this type of rejection was only observed 2 days after transplantation. In other terms, the only event-free xenograft survival time was when xenoantibodies were absent because the appearance of the initial xenorejection injuries occurred when goats again displayed anti-pig xenoantibodies in their sera. It might be possible that these xenoantibodies may have stimulated natural killer cells or a T-cell-mediated process to induce further endothelial cell dysfunction and procoagulant activity.

All these rejection injuries appeared earlier, and the cellular-mediated rejections were more vigorous in goats belonging to group 3 than to group 2, and this fits well with the fact that the entire cardiac output was flowing through the pig xenograft. Indirectly, these observations involve that T-cell-mediated xenograft rejection is often more severe than T-cell-mediated allograft rejection ${ }^{20}$ and that, in vivo, pig xenografts are almost certain to provoke vigorous direct or indirect $\mathrm{T}$ cell xenoresponses within the first week after transplantation. Ultimately, xenografts become completely destroyed by an ischemic necrosis, and this mainly occurs when the titers of anti-pig xenoantibody return to pretransplantation values. Of note, the ischemic necrosis typically spared recipients' bronchial, arterial, and left atrium stumps, mirroring to some extent the observations reported in the precyclosporin lung allotransplantation era and demonstrating that conventional immunosuppressive agents may be less effective at prolonging xenograft survival than at prolonging allograft survival.

We observed that goat serum contains natural anti- bodies that bind to pig antigens whereas the opposite does not hold, as was already observed in other species combinations. ${ }^{14}$ Moreover, the presence of natural antibodies was correlated with the severity and tempo of graft rejection, because hyperacute rejection was seen in pig-to-goat xenografts (group 1) but not in goat-topig xenografts (group 4). These results are in accordance with previous work that reported the absence of hyperacute rejection in pig-to-newborn goat cardiac xenografts because of very low levels of natural antibodies in newborn. ${ }^{13}$ They also allow to define of the pig-to-goat combination as a discordant xenograft model, whereas the goat-to-pig model would be concordant, according to a classification based on the immunologic response. ${ }^{21}$

In summary, we have developed an orthotopic $\alpha$-Gal antibody-free lung xenotransplantation model that reports a refractory vasogenic shock and pulmonary hypertension and dysfunction after $7 \pm 3$ hours on pig xenograft reperfusion. This form of hyperacute rejection is consistently prevented by the immunodepletion of goat anti-pig xenoantibodies before xenograft implantation. Unfortunately, this prevention is only temporary because both humoral- and cellular-mediated rejection occur and evolve to xenograft necrosis once goats resynthesize anti-pig xenoantibodies. This pig-to-goat combination could be a valuable working discordant model for the evaluation of strategies aimed at preventing antibody-mediated rejection mechanisms.

We thank Chantal Verriest, Rémi Burel, Hegésippe Langouste, Bruno Baudet, and Aline Perrin for technical assistance and Denis Petraz for photographic contributions.

\section{REFERENCES}

1. Platt JL, Vercelotti GM, Dalmasso AP. Transplantation of discordant xenografts: a review of progress. Immunol Today 1990;11:450-6.

2. Pierson RN, Kasper-Konig W, Tew DN, Young VK, Dunning JJ, Horsley $\mathrm{J}$, et al. Hyperacute lung rejection in a pig-to-human transplant model. Transplantation 1997;63:594-603.

3. Macchiarini P, Mazmanian GM, Oriol R. Ex vivo lung model of pig to human hyperacute xenograft rejection. J Thorac Cardiovasc Surg 1997;114:315-25.

4. Dagget CW, Yeatman M, Lodge AJ, et al. Total respiratory support from swine lungs in primate recipients. J Thorac Cardiovasc Surg 1998;115:19-27.

5. Dagget CW, Yeatman M, Lodge AJ, Chen EP, van Trigt P, Byrne $\mathrm{GW}$, et al. Swine lungs expressing human complement-regulatory proteins are protected against pulmonary dysfunction in a human plasma perfusion model. J Thorac Cardiovasc Surg 1997; 113:390-8.

6. Macchiarini P, Oriol R, Azimzadeh A, et al. Evidence of human non- $\alpha$-galactosyl antibodies involved in the hyperacute rejection of pig lungs and their removal by pig organ perfusion. $\mathrm{J}$ Thorac Cardiovasc Surg 1998;116:831-43. 
7. Galili U, Shohet SB, Kobrin E, Stults CLM, Macher BA. Man, apes, and old world monkeys differ from other mammals in the expression of $\alpha$-galactosyl epitopes on nucleated cells. J Biol Chem 1988;263:17755-62.

8. Oriol R, Candelier JJ, Taniguchi S, et al. Major carbohydrate epitopes in tissues of domestic and african wild animals of potential interest for xenotransplantation research. Xenotransplantation 1999;6:79-89.

9. Enzan K, Wang Y, Schultz E, et al. Pulmonary hemodynamic reaction to foreign blood in goats and rabbits. J Appl Physiol 1991;71:2231-7.

10. Bailey LL, Jang J, Johnson W, Jolley WB. Orthotopic cardiac xenografting in the newborn goat. J Thorac Cardiovasc Surg 1985;89:242-7.

11. Lipovetsky G, Fenoglio JJ, Gieger M, Srinivasan MR, Dobelle WH. Coronary artery anatomy of the goats. Artif Organs 1983;2:238-45.

12. Feistkorn G, Nagel A, Jessen C. Circulation and acid-base balance in exercising goats at different body temperatures. J Appl Physiol 1984;57:1655-61.

13. Xu He, Gundry SR, Hill AC, et al. Prolonged discordant cardiac xenograft survival in newborn recipients. Circulation 1997;96 (Suppl):II364-7.

14. Azimzadeh A, Wolf K, Thibaudeau D, Cinqualbre J, Soulillou JP, Anegon I. Comparative study of target antigens for primate xenoreactive natural antibodies in pig and rat endothelial cells. Transplantation 1997;64:1166-74

15. Azimzadeh A, Meyer C, Watier H, et al. Removal of primate xenoreactive natural antibodies by extracorporeal perfusion of pig kidneys and livers. Transplant Immunol 1998;6:13-22.

16. Scherrer L, Leventhal JR, Matas AJ, Dalmasso AP. Evidence that rat xenoreactive antibodies recognize multiple protein antigens on guinea pig endothelial cells and platelets. Transplantation 1994;58:458-66.

17. Holzknecht ZE, Platt JL. Identification of porcine endothelial cell membrane antigens recognized by human xenoreactive natural antibodies. J Immunol 1995;154:4565-75.
18. Hammer C. Immunosuppression in xenotransplantation. Transplant Proc 1996;28:3017-20.

19. Lawson JH, Platt JL. Molecular barriers to xenotransplantation. Transplantation 1996;62:303-10.

20. Dorling A, Riesbeck K, Warrens A, Lechler R. Clinical transplantation of solid organs. Lancet 1997; 349:867-71.

21. Calne RY. Organ transplantation between widely disparate species. Xenotransplantation 1994;2:79-83.

\section{Discussion}

Dr Mark K. Ferguson (Chicago, Ill). You have shown that you get very complete immunodepletion with the absorption model that you have used. Is there some commercial or mechanical way that you can achieve that same result?

Dr Macchiarini. This way could be achieved in the swineto-human combination with $\alpha$-Gal antibody columns. However, in this combination we do not need anti-Gal columns. Commercially, yes. You need to develop a system like a membrane oxygenator incorporating carbohydrates to absorb target antibodies.

Dr David M. Kulick (Minneapolis, Minn). In the vascular rejection of your xenografts did you look at immunohistochemistry or fluorescence-activated cell sorter analysis to identify the types of lymphocytes or mononuclear cells that were infiltrating around the vascular structures in the lungs that were transplanted?

Dr Macchiarini. No. We did only simple histologic examination that showed leukocyte infiltration.

Dr Kulik. In the pig-to-primate combination for heart transplantations, we have seen a marked increase in CD68positive cells, and I was curious if you had seen that in the lungs as well.

Dr Macchiarini. No.

\section{Authoritative}

The Journal of Thoracic and Cardiovascular Surgery is the most frequently cited thoracic/cardiovascular surgery journal in the Science Citation Index. An article in JTCVS is sited on average almost twice as often as those in the closest cardiothoracic journal. 